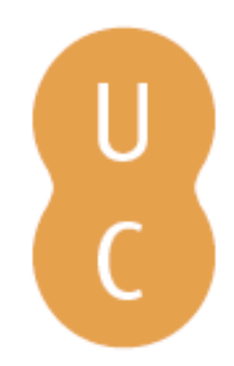

\title{
Rompalina
}

\section{Repegando o fio de Ariadne... à conversa com quatro cientistas e suas viagens}

Autor(es): $\quad$ Ferreira, Gabriela Tristão; Bolinhas, Maria Inês

Publicado por: Imprensa da Universidade de Coimbra

URL

persistente:

URI:http://hdl.handle.net/10316.2/32443

DOI:

DOI:http://dx.doi.org/10.14195/978-989-26-0469-5_34

Accessed : $\quad$ 26-Apr-2023 02:19:51

A navegação consulta e descarregamento dos títulos inseridos nas Bibliotecas Digitais UC Digitalis, UC Pombalina e UC Impactum, pressupõem a aceitação plena e sem reservas dos Termos e Condições de Uso destas Bibliotecas Digitais, disponíveis em https://digitalis.uc.pt/pt-pt/termos.

Conforme exposto nos referidos Termos e Condições de Uso, o descarregamento de títulos de acesso restrito requer uma licença válida de autorização devendo o utilizador aceder ao(s) documento(s) a partir de um endereço de IP da instituição detentora da supramencionada licença.

Ao utilizador é apenas permitido o descarregamento para uso pessoal, pelo que o emprego do(s) título(s) descarregado(s) para outro fim, designadamente comercial, carece de autorização do respetivo autor ou editor da obra.

Na medida em que todas as obras da UC Digitalis se encontram protegidas pelo Código do Direito de Autor e Direitos Conexos e demais legislação aplicável, toda a cópia, parcial ou total, deste documento, nos casos em que é legalmente admitida, deverá conter ou fazer-se acompanhar por este aviso. 
Ana Leunar Pereira João Rui Pita

[ Coordenaçä̃ ]
Rotas da Natureza

Cientistas

Viagens

Expedifgũes

Instituip̧ües

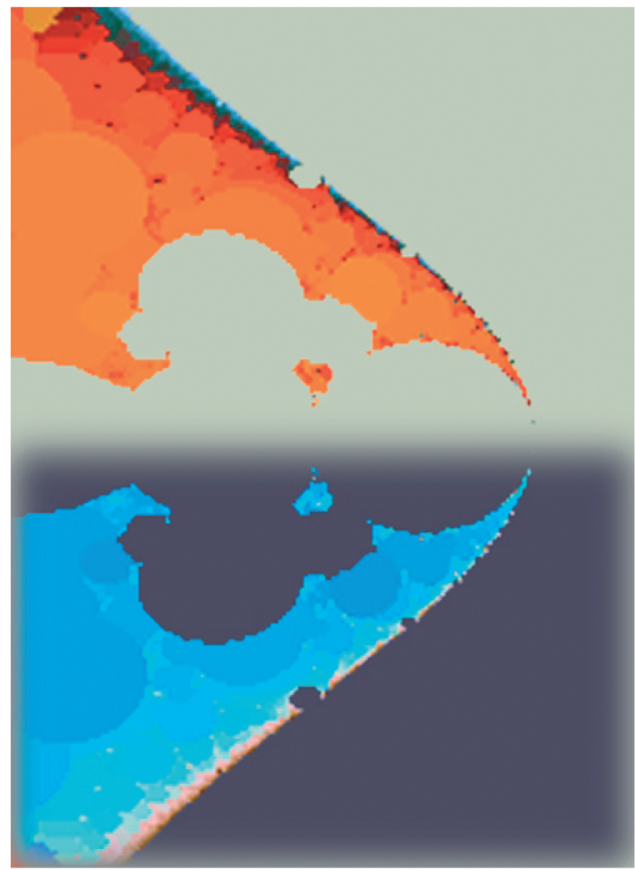




\section{Coordenaçáo Científica da Colecção Ciências e Culturas}

João Rui Pita e Ana Leonor Pereira

Os originais enviados são sujeitos a apreciação científica por referees

\section{Coordenação Editorial}

Maria João Padez Ferreira de Castro

\section{Edição}

Imprensa da Universidade de Coimbra

Email:impresauc@ci.uc.pt

URL: http://www.imp.uc.pt • Normas de publicação de colecçôes

\section{Design}

António Barros

Pré-Impressáo

António Resende

Imprensa da Universidade de Coimbra

\section{Capa}

António Barros, com imagem de E. M. de Melo e Castro, 2003 [Fractal original gerado no Fractint com tratamento no Photoshop 7.0]; Cortesia: António Barros

Impressão e Acabamento

SerSilito • Maia

\section{ISBN}

978-989-8074-12-6

\section{Depósito Legal}

Obra publicada com a colaboraçáo de:
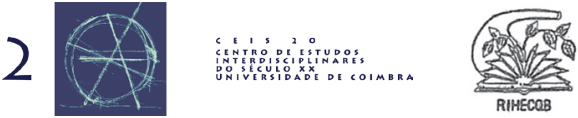

Obra publicada com o apoio de:

FCT Fundação para a Ciência e a Tecnologia

MINISTÉRIO DA CIÊNCIA, TECNOLOGIA E ENSINO SUPERTOR Portug

Programa Operacional Ciência, Tecnologia, Inovação do Quadro Comunitário de Apoio III
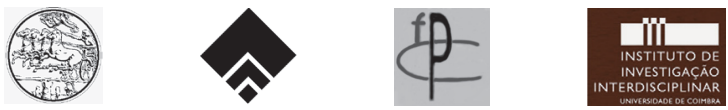

\section{Baxter}

(c) 2006, Imprensa da Universidade de Coimbra 
João Rui Pita

Ana Leonar Pereira

(Courdenação)

Rotas da Natureza

Cientistas

Viagens

Expediçũes

Instituiç̃̃es

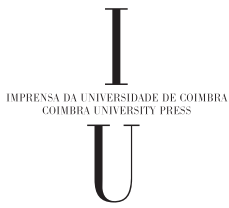

- colmbra 2006 
(Página deixada propositadamente em branco) 


\author{
Gabriela Tristão Ferreira* e Maria Inês Bolinhas** \\ * Arquitecta, Portugal \\ ** Universidade Católica Portuguesa, Portugal
}

\title{
RePEgando o fio de ARIADne... À CONVERSA COM QUATRO CIENTISTAS E SUAS VIAGENS
}

Reza a mitologia grega que, graças ao fio oferecido por Ariadne, se salvou Teseu da morte da desorientação no labirinto. Quer o labirinto, quer o engenho, são metáforas vitais, como referiu Ernst Cassirer, que, no séc. XX, alertou a comunidade pensante para a urgência duma filosofia da cultura empenhada em lançar luz sobre a confusão existente no campo cognitivo, dominado pela dissociação e isolamento epistemológicos, ameaçadores da compreensão do homem por si mesmo e, por arrasto, da vida humana enquanto tal ${ }^{1}$. Chamámos o fio de Ariadne para o título da nossa reflexão porque, destacando a fundamentação da importância que um aspecto particular do modus faciendi científico assume em quatro áreas do saber contemporâneo, procurámos encontrar uma unidade de sentido epistemológico entre as diferentes perspectivas sem, contudo, renunciar às suas especifidades.

Questionando a pertinência da viagem expedicionária no trabalho científico hodierno - já que, graças à sofisticação dos meios técnicos, é hoje possível fazer a quase totalidade das observações a milhares de quilómetros de distância - entrevistámos quatro investigadores que têm nos seus curricula viagens em trabalho de campo ${ }^{2}$.

\footnotetext{
${ }^{1}$ Ernst Cassirer, Ensaio sobre o Homem, trad. de Carlos Branco, Lisboa, Guimarães Editores, 1995'; p. 30: «Nenhuma época anterior esteve em posição tão favorável no tocante às fontes do nosso conhecimento da natureza humana. A psicologia, a etnologia, a antropologia e a história reuniram um corpo de factos espantosamente rico e em constante crescimento. Os nossos instrumentos técnicos para observação e experiência melhoraram imensamente e as nossas análises tornaram-se mais agudas e penetrantes. Parecemos, todavia, não ter encontrado ainda um método para dominar e organizar este material. Comparado com a nossa abundância, o passado pode parecer muito pobre, mas a nossa riqueza de factos não é necessariamente riqueza de pensamentos. A não ser que consigamos encontrar um fio de Ariadne que nos conduza para fora do labirinto, não poderemos ter uma verdadeira visão do carácter geral da cultura; ficaremos perdidos numa massa de dados desconexos e desintegrados a que parece faltar toda a unidade conceptual». Itálicos nossos.

${ }^{2} \mathrm{O}$ texto que se segue é a síntese da investigação realizada no âmbito do seminário em «Cosmologia e Ambiente», orientado pelas Professoras Doutoras Alexandra Escudeiro e Ana Luísa Janeira (2º semestre do ano lectivo 2002/2003), do curso de mestrado «A Acção na Filosofia Ocidental: A Acção Ética, Social, Política e Ambiental» da Área Científica de Filosofia da UCP (Lisboa). Encontra-se disponível em http:// www.amazonia.no.sapo.pt([2003] projecto coordenado pela Doutora Ana Luísa Janeira) a investigação completa - que versa também sobre as diferentes posições dos entrevistados sobre outros temas de relevân-
} 
Optámos, portanto, pelo testemunho directo, oral, do cientista-viajante; procurámos, efectivamente, a Ciência feita na primeira pessoa, conversando com os dois geólogos João Mata ${ }^{3}$ (Geologia Pura) e Fernando Marques ${ }^{4}$ (Geologia Aplicada), com o biólogo e ilustrador científico Pedro Salgado ${ }^{5}$ e com a socióloga Alexandra Arvéola ${ }^{6}$. A selecção não foi aleatória: escolhemos a Ciência das coisas não vivas, a Ciência das coisas vivas - neste caso unida à sensibilidade estética - e a Ciência das coisas conscientes, agrupadas em sociedade.

\section{A viagem}

Poder-se-á fazer Ciência sem o recurso à viagem? Isto porque parece ter sido comum o papel da experiência in loco do observador com o objecto observado enquanto paradigma da práxis científica. Será ainda a viagem indissociável da existência humana? Estas foram algumas das questões que tentamos deslindar, analisando o modelo de abordagem científica presente em cada um dos quatro investigadores entrevistados, os quais, quando confrontados com a importância da viagem no «fazer» Ciência, foram unânimes quanto ao carácter essencial da investigação no terreno na colecta de dados para posterior tratamento e investigação. As suas teses partiriam duma actividade racionalista a posteriori fortalecida pelos sentidos, enquanto auscultadores privilegiados no contacto directo, empírico, com o objecto de estudo, experiência geradora de uma ligação afectiva pessoal e intransmissível. Paradigma este diametralmente oposto à epis-

cia para a prática científica (a título de exemplo, salientemos a problemática entre ciência e verdade/ética/ interdisciplinaridade) - e também os apêndices - que englobam o modelo e a transcrição completa das entrevistas, a matéria-prima da nossa reflexão. Por todas as citaçóes no corpo de texto se encontarem nos anexos acessíveis no site atrás indicado, não as referimos em nota de rodapé.

${ }^{3}$ Docente, desde 1982, do Dep. de Geologia da Universidade de Lisboa. A sua investigação centra-se essencialmente em dois temas: caracterização magmática e metamórfica da evolução do sector ibérico varisco; processos de génese e evolução dos magmas oceânicos intraplaca - suas implicações para a composição e evolução do manto. O grande interesse que lhe despertam os processos de formação das ilhas oceânicas reflecte-se na tese de doutoramento, feita sobre a ilha da Madeira - intitulada Petrologia e geoquimica das lavas da Ilha da Madeira: implicações para os modelos de evolução mantélica - e na sua participação em missões geológicas nos arquipélagos das Canárias (1988, 1990), São Tomé e Príncipe (1995) e Cabo Verde (1998, 2001).

${ }^{4}$ Mestre (1988) e Doutor (1997) em Geotecnia, é docente, desde 1984, do Dep. de Geologia da Universidade de Lisboa. Conta com vários trabalhos de campo efectuados no nosso país. Tem desenvolvido actividades de investigação e docência na área da Geologia de Engenharia, com particular incidência no estudo da evolução de arribas litorais, na estabilidade de taludes, no desenvolvimento de técnicas de fotointerpretação e na caracterização geotécnica de solos rijos e rochas brandas.

${ }^{5}$ Formado em Biologia pela Universidade de Lisboa, apostou em aliar a Ciência à arte, sendo o impulsionador da ilustração científica portuguesa. O ilustrador Pedro Salgado é também professor de desenho.

${ }^{6}$ Licenciada em Sociologia pelo ISCTE, obteve na mesma instituição (onde é investigadora do Centro de Estudos Africanos), o grau de Mestre com a tese A configuração da paisagem organizacional e articulação entre agentes externos, em Cuamba, Moçambique, onde fez trabalho de campo. 
téme racionalista desafectada do passado: em Lévi-Strauss ${ }^{7}$ a viagem, a ida ao terreno, mais não seria do que a confirmação das teses há muito desenvolvidas na segurança e pacatez no gabinete do investigador. Ao iniciar o relato das suas expedições ao Brasil, refere a «repulsa» que sentiu pelos expedicionários seus contemporâneos, criticando a aproximação empirista à Ciência exaltada no relato de trivialidades gastas nas semanas de expedição que, segundo ele, acabavam por escravizar - pelo tempo perdido - o investigador, limitando o atingir imediato do seu objecto de estudo. Era a recusa da experiência lúdico-emocional do expedicionário documentalista.

Pretendemos mostrar que, para além de muitas outras diferenças, o cientista-viajante actual enfrenta alguns dos desafios que o expedicionário primitivo - esse argonauta, ser-homem - viveu ao partir para um outro mundo, desconhecido, hostil, sendo forçado a adaptar-se e a maravilhar-se com toda a dynamis rodopiante do locus envolvente. Este é, afinal, o movimento essencial da existência humana e da sua aventura no planeta, mas também o é de todos os seres que com ele habitam esse espaço físico, forçosamente vivo, cuja ordem reguladora é a constante mutação numa adequação mútua mediante fluxos de energia circulares. A viagem é existência. É auto-conhecimento; mundividência; experiência consciente da vida.

\section{Os conceitos de naturalismo e de natureza vistos pelos investigadores}

A consciencialização da existência de um mundo natural, do qual fazemos parte - a Natureza percepcionada, objectivada como o «outro» com que convivemos - só é atingida quando esse mundo é percebido enquanto mundo de fenómenos, em movimento, dinâmico, o mundo vivo, existente. Por esta razão, quando questionados sobre os conceitos naturalismo e Natureza, os diversos investigadores mostraram-se coincidentes relativamente ao entendimento sobre os mesmos. Se para P. Salgado, naturalismo é «tudo o que tem a ver com o ser natural», do qual o homem faz parte, e que tem a ver com

[...] a História Natural, a Biologia, em particular, mas também com a Geologia e [...] compreensão do tempo. Uma vez que o tempo é fundamental para desfazer a arrogância, para não ficarmos aqui a olhar para o nosso próprio umbigo [...] porque na verdade, estamos todos de passagem,

para J. Mata, o planeta Terra é uma entidade móvel e dinâmica, concorrendo para a definição dada pelo biólogo anterior isto porque a Terra vai evoluindo e nesse aspecto é um ser vivo. A esse respeito afirma que «mesmo os colegas paleontologistas estudam nas rochas sedimentares os tipos de formas de vida que existiram. Nesse aspecto não

${ }^{7}$ C. Lévi-Strauss, Tristes Trópicos, trad. Gabinete Literário de Ed. 70, Lisboa, Ed. 70, 19931; p. 12 : «[...] ser explorador é agora uma profissão a qual não consiste, ao contrário do que poderia parecer, em encontrar, ao final de anos e anos de estudo, factos até então ocultos, mas sim em percorrer um grande número de quilómetros, juntando diapositivos e filmes, de preferência coloridos, que permitirão lotar uma sala, durante vários dias seguidos, com uma multidão de ouvintes para os quais frases ocas e banalidades irão se transmutar em revelações, pelo simples facto de o autor, em vez de situá-los em local próximo, tê-las santificado com um percurso de 20000 quilómetros». 
é muito diferente da biologia. O que eles estudam é a natureza morta, é a Terra nos seus mais variados aspectos e na sua relação com os seres vivos». F. Marques partilha igualmente desta posição acerca do planeta, exemplificando que «todos os dias, e mais do que uma vez ao dia, temos deformaçôes causadas pelo efeito da maré». Já A. Arvéola vê o homem como um ser natural, mas considera que há casos e casos, porque se interroga acerca do "grau» desse naturalismo. As suas reservas, vão sem dúvida, consoante o caso, para a evolução, ou regressão, de que a nossa espécie está a ser alvo.

P. Salgado, porém, exclui o homem do conceito de Natureza. Considera que «dentro da Natureza o homem, como ser natural é um elemento de distúrbio, auto-destrutivo - obtuso a ponto de não ver que ao destruir a natureza se vai destruir a si próprio». Visão idêntica é partilhada por A. Arvéola, referindo que quem trabalha em África dificilmente terá uma visão optimista, falando mesmo em «Afro-pessimismo... provavelmente porque lá as coisas são muito mais evidentes do que são aqui!», não auspiciando nada de positivo no percurso civilizacional humano. Do mesmo modo pensa F. Marques, para quem, contudo, o protagonismo atribuído actualmente à Ecologia poderá, talvez, atenuar a "acção destruidora do homem», ou não... embora tenha dúvidas quanto a essa "acção destruidora» estar integrada na própria evolução.

\section{O caderno de campo}

No fazer ciência dos nossos quatro cientistas-viajantes, o "caderno de campo" apresenta uma característica comum a todos os investigadores. O seu uso é feito posteriormente como auxiliar de memória, relativamente às notas e apontamentos tirados no local pelo cientista, que tanto podem ser números, como fórmulas químicas, coordenadas de localização das amostras recolhidas, ou ainda desenhos ou esquemas explicativos da composição ou organização dos materiais recolhidos; podendo também servir de testemunho para outros investigadores que pretendam enveredar pelas pistas legadas pelos colegas. O caderno de campo é um registo, sempre mais ou menos normalizado, consoante a área científica, que contém as motivações, impressões e objectivos particulares do investigador, assim como as metodologias da expedição realizada, possuindo um cariz particular, porque personalizáveis e intercambiáveis. Os cadernos de campo são ferramentas indispensáveis de trabalho, passíveis de poderem adquirir um certo pendor artístico provido de rigor científico.

\section{A objectividade e a afectividade}

Um dos maiores problemas que se põe à validade do conhecimento, à sua objectividade ou subjectividade, é o da afectividade. Quando o cientista se deixa levar pelas suas valorações e emoções subjectivas, trai a ideia de ciência como saber válido em si e por si mesmo. Por outra parte, a evidência de que a própria actividade da investigação principia com o desejo ${ }^{8}$ coloca a própria dimensão afectiva como prévia

\footnotetext{
${ }^{8}$ Só investigamos e valorizamos a investigação porque consideramos que o conhecimento é bom, porque gostamos de conhecer. Por outra parte, quando escolhemos um objecto de estudo, escolhemo-lo porque nos interessa.
} 
à investigação. As razôes para investigar só são boas razôes porque as reconhecemos como tais.

A viagem evoca todas estas questōes, ao pôr o cientista no trabalho de campo, em contacto imediato com o objecto de estudo, até então conhecido mediatamente. Porque toda a experiência humana é, à vez e indissociavelmente, cognitiva e afectiva, concluímos que na viagem expedicionária - quer no âmbito das ciências puras, quer no das aplicadas, quer ainda no das ditas exactas, como no das ditas humanas - se cruzam as dimensões díspares, mas complementares, da inteligência e do afecto. $\mathrm{O}$ sujeito cognoscente encontra-se diante de algo (uma rocha/falésia, uma planta/animal, uma pessoa/sociedade) que o toca na dimensão prévia à epistemológica: a da pessoa.

Os nossos investigadores partilharam connosco como se vive e se gere a coabitação da actividade científica com a esfera do afecto. J. Mata afirmou que a prática da investigação em Geologia implica experiências afectivas, pois mesmo quando o nosso objecto de estudo não interage connosco, como é o caso do mineral, o investigador reage emocionalmente ao que se oferece aos olhos e ao pensamento:

- Quando olho para esta pedra, eu digo que é uma pedra. O Professor dir-me-á que ela é um corpo constituída por X elementos químicos. Ou não?

JM - Nós afeiçoamo-nos a esta pedra... Eu trabalhei muitos anos em trabalho de campo na Madeira. Quando não estava no campo, estava cá e pensava na Madeira. A Madeira ocupa em mim um lugar, e ocupará sempre, devido a ter trabalhado lá para o meu doutoramento.

F. Marques, afirmou que também na área da Geologia Aplicada é complicado lidar com os afectos:

Estou a lembrar-me de um caso em que essa questão se me pôs... e eu procurei, também, tratar do assunto de uma maneira mais fria e mais distante. Isso deu-se particularmente nos planos de ordenamento da orla costeira. [...] De facto, a costa é de uma beleza espantosa! Estando envolvido nos consórcios com a missão de definir faixas de risco e faixas de proteç̧ão [...], eu poderia ter a tentação de exorbitar das minhas competências e produzir faixas que não fossem única e exclusivamente baseadas em princípios de ordem técnica $[\ldots]$.

O questionamento sobre a interferência da afectividade na consecução da exactidão do conhecimento assume as proporções simultaneamente mais altas e imperativas quando toca à investigação sobre aquele objecto de estudo que me olha, que me interpela, que joga comigo: o Outro ser humano. A. Arvéola deu-nos conta das dificuldades que defronta:

A imparcialidade científica é muito difícil de conseguir. [...] No nosso caso, tudo se baseia na sinceridade [...]. Quando vou a uma organização, não lhes digo que estou ali para resolver os problemas deles. Explico o que é que lá estou a fazer e depois logo vejo a empatia [...] e a disponibilidade que eles mostram para colaborar. Como é no meio das organizaçóes, é mais fácil ter um certo distanciamento, porque a pessoa que está ali representa um cargo, assume uma função. [...] Agora, quando vamos para o 
campo e estamos com os agricultores, onde vivemos com eles, comemos com eles, torna-se mais complicado; sobretudo porque aí têm que se estabelecer relações de confiança muito fortes se se quiser fazer um trabalho que seja minimamente aproximado das situações verídicas. De outro modo, só saberemos de coisas que não nos interessam, o que faz com que se perca a própria pertinência da investigação.

Para este tipo de investigação em Ciências Humanas, o investigador, para além de ter que gerir os seus próprios afectos (se estes dominam, a investigação fracassa), deverá também ter sabedoria e honestidade suficientes para conseguir cativar os dos outros. A condição bi-direccional torna esta experiência simultaneamente rica e desgastante.

No caso da actividade profissional de P. Salgado, a ligação afectiva com o objecto de estudo assume outros contornos, enquanto motivadora do próprio desenho:

Eu sempre me distanciei um bocadinho dessas escolas matemáticas, desses modelos matemáticos para entender fenómenos ecológicos [...]. No estudo da Ecologia que se faz por aí, aplicam-se modelos matemáticos para entender como é que as coisas funcionam, e muita gente acaba por chegar às mesmas conclusões às quais os naturalistas já tinham chegado! Tinham observado durante vinte ou trinta anos de experiência no campo e já então percebiam como as coisas funcionavam!

O afecto e a contemplação têm relação com um outro tipo, entretanto desvalorizado, de conhecimento, baseado sobretudo na observação. O contaco directo com o objecto de estudo permite outro modo de fazer ciência.

\section{Nota conclusiva}

No seguimento da afirmação nietzscheana da inexistência da arte pela arte, cremos também na inexistência da ciência pela ciência. Como toda a actividade humana, a ciência é despoletada pela experiência, e continuamente alimentada e movida pelos afectos nela concorrentes. Todo o conhecimento é, por conseguinte, conhecimento da pessoa, e a pessoa é, por si, viagem. O que impóe o alargamento e aprofundamento do paradigma científico. 
(Página deixada propositadamente em branco) 


\section{Colecçãa \\ 2 Ciências e Culturas Caimbra 2006}

